\title{
Interaction between ventricular loading and repolarisation: relevance to arrhythmogenesis
}

\author{
Peter Taggart, Peter Sutton, Max Lab
}

\begin{abstract}
Abnormality of left ventricular wall motion is a major predictor of sudden cardiac death in patients with coronary disease ${ }^{12}$ or after myocardial infarction. ${ }^{34}$ Death is usually caused by arrhythmia. ${ }^{5}$ Some patients with chronic heart failure die as a result of profound bradycardia and/or asystole ${ }^{6}$ but there is also a high incidence of lethal or potentially lethal ventricular arrhythmia. ${ }^{7-10}$ Moreover, the incidence of ventricular arrhythmia is high in patients with hypertension, ${ }^{11-13}$ and in patients with aortic stenosis. ${ }^{14}$ The mechanism for the association between wall motion or mechanical load abnormality in these patients and arrhythmia is unclear. One possibility is a direct interaction between mechanical and electrical events whereby myocardial load or strain influences the electrophysiology ${ }^{15}$-that is, the excitability and refractoriness of the myocardial cells. Such a mechanism has been shown in isolated tissues and in animal studies $^{1516}$ and is now receiving attention in humans. ${ }^{1718}$ This mechanism if present could well be implicated in the genesis of human arrhythmias ${ }^{19}$ particularly if it could be shown that there was a differential response between areas of abnormal wall motion and normal wall motion, as has been shown in studies of dogs with chronically infarcted hearts. ${ }^{20}$

To date three studies in humans provide evidence for a relation between stretch or strain and the electrophysiological behaviour of myocardial cells. ${ }^{17821}$ One of these studies also shows that abnormality of wall motion can significantly modify this relation. ${ }^{21}$
\end{abstract}

Possible arrhythmogenic mechanisms There are several ways by which mechanically induced electrophysiological effects may be arrhythmogenic in the clinical setting of ischaemia, acute infarction, or in hearts subject to pressure/volume overload.

Department of

Middlesex Hospital,

London

P Taggart

P Sutton

M Lab

Correspondence to Dr P Taggart

Department of Cardiology,

The Middlesex Hospital, Mortimer Street, London WIN 8AA.

Accepted for publication 15 August 1991
Regional asynergic or paradoxical wall motion occurs early during myocardial ischaemia. ${ }^{22-24}$ Patients who develop an aneurysm within 48 hours-that is, an area of systolic akinesia or dyskinesia with a distinct systolic deformity and preserved adjacent wall motion-are particularly at risk of sudden death. ${ }^{25}$ It has been suggested that because activation of injured muscle is slow, it may still be in electrical diastole when the surrounding muscle is in systole. ${ }^{26}$ As the ventricle contracts the injured segment would be stretched and this would induce electrical activation in this area. ${ }^{27}$ This electrical wavefront would again propagate slowly to the surrounding normal tissue, which by that time would be no longer refractory and so would be reactivated.

\section{MECHANICALLY INDUCED REENTRY}

An important arrhythmogenic mechanism is reentry. ${ }^{2629}$ The basic principles underlying the development of a reentry circuit may be illustrated by the following model. A propagating impulse may meet an obstacle-for example, infarcted muscle or scar tissue. The impulse would then divide into two and pass round either side. If conduction around the obstacle is impaired, conduction may fail down one limb (decremental conduction) and be blocked. If the impulse travelling down the other limb is slowed it may reach the distal part of the blocked limb after a delay which has allowed time for the blocked limb to become re-excitable. The impulse may then travel backwards up this limb and then continue round the obstacle in a circular fashion following in the wake of the change in muscle from the refractory to the excitable state. This constitutes a reentry circuit which is autonomous and may take over the activation of the ventricle.

An obstacle does not necessarily need to be an anatomical one: it could be created by an inhomogeneous alteration in the refractoriness in neighbouring fibre groups which may induce "functional" unidirectional block. It is apparent therefore from the above model that factors which create regional differences in conduction and excitability would be expected to encourage the development of reentry. In this context it has been shown that conduction block may be induced by local differences in refractory period of the order of 11-16 ms in atrial tissue ${ }^{30}$ and of the order of $10-20 \mathrm{~ms}$ in ventricular muscle. ${ }^{31}$ The path of a reentry circuit is usually, in the border zone between scar tissue (or non-conductive muscle) and normal myocardium. Local mechanical stress has been shown to be magnified by up to four times at the junction between normal myocardium and scar tissue by a process known as 
stress amplification. ${ }^{32}$ This may exaggerate regional electrical inhomogeneity at border zones and this territory would be particularly susceptible to mechanically induced electrophysiological effects.

\section{ABNORMAL CURRENT FLOW}

Another possibility is abnormal current flow. Inhomogeneous wall stress or strain, particularly marked in the presence of ischaemia ${ }^{22-24}$ could produce local electrical inhomogeneity by contraction-excitation feedback. For example one area could have wall motion that is out of phase with an adjacent area (dyskinesia). The two areas would then generate current by virtue of the potential differences created by the now out of phase action potentials which would stimulate adjacent cells during the period of enhanced excitability. ${ }^{28}$

\section{AFTERDEPOLARISATIONS}

Early afterdepolarisations are seen as inflections of the normal repolarisation phase of the action potential. ${ }^{162131}$ If such inflections are large enough they can trigger an early beat and they have been implicated in the genesis of arrhythmias. The interpretation of inflections in the downstroke of the monophasic action potential that is characteristic of early afterdepolarisations, however, is contentious because it is impossible to exclude a mechanically induced artefact caused by passive electrical changes at the tissue/electrode interface..$^{334}$ Nonetheless, several observations support the possibility that these afterdepolarisations are not an artefact. ${ }^{35}$ Also the monophasic action potential electrode reliably records early afterdepolarisations in vivo under circumstances known to produce them in vitro, when they are recorded by microelectrodes. ${ }^{37} 38$

\section{CELLULAR MECHANISMS}

Cellular mechanisms may involve stretch and fibre excursion. ${ }^{15}$ Stretch would invoke a nonspecific permeability change perhaps via stretch activated channels ${ }^{39}$ and fibre excursion would invoke a change in intracellular calcium. ${ }^{40}$ It may be that enhanced excursion deactivates force by reducing the affinity of calcium for troponin C. Calcium comes off the myofilaments and increases sarcoplasmic concentrations to prolong the action potential via electrogenic sodium-calcium exchange ${ }^{41}$ or calcium activated currents. ${ }^{42}$

\section{Therapeutic relevance}

Electromechanical interactions may be relevant to the high incidence of sudden death caused by ventricular arrhythmia in patients with impaired left ventricular function. ${ }^{1-5}$ Such interactions may also be relevant in patients with acute ischaemia, in whom local wall motion abnormality is a usual early feature..$^{22-24}$ Several factors may interrelate with electromechanical interaction. For example, arrhythmia may be initiated by an extrasystole or the subsequent beat. Both the extrasystolic and the post extra-systolic impulse have an altered cycle length and are associated with altered force of contraction. In addition these impulses may induce a sudden change in direction of propagation which in turn may alter the orientation of wall stress between areas of normal and ischaemic myocardium or between neighbouring areas of normal and abnormal wall motion.

Therapeutic interventions designed to manipulate preload and afterload are now commonly used, as are drugs that influence the inotropic state of the ventricle. In fact, load reduction, a pure mechanical intervention, may turn out to be an antiarrhythmic intervention in congestive heart failure. ${ }^{43}$ An important consideration would be the relative effects of a drug given to alter loading conditions on the adjacent normal and abnormal segment of ventricle. It may be that such a medication would have an antiarrhythmic effect in one area and an arrhythmogenic effect in another area with a different force-tension velocity profile. Understanding of these mechanisms involving electromechanical interaction may be important for the future development of therapeutic strategies.

1 Weaver WD, Lorch GS, Alvarez HA, Cobb LA. Angiographic findings and prognostic indicators in patients resuscitated from cardiac death. Circulation 1976;54: 895-900.

2 Schultz RA, Strauss HW, Pitt B. Sudden death in the year following myocardial infarction: relation to ventricular prewature contractions in the late hospital phase and left ventricular ejection fraction. $A m$ J Med 1977;62:192-9.

3 Multicentre Postinfarction Research Group. Risk stratification and survival after myocardial infarction. $N$ Engl $J$ Med 1983;309:331-6.

4 White HD, Norris RM, Brown MA, Brandt PWT, Whitlock RML, Wild CJ. Left ventricular end systolic volume as the major determinant of survival after recovery from myocardial infarction. Circulation 1987;76:44-51.

5 Liberthson RR, Nagel EL, Hirschman JC, Nussenfeld SR, Blackbourne BD, Davis JH. Pathophysiologic observations in prehospital ventricular fibrillation and sudden cardiac death. Circulation 1974;49:790-8.

6 Luu M, Stevenson WG, Stevenson LW, Baron K, Walden J. Diverse mechanisms of unexpected cardiac arrest in advanced heart failure. Circulation 1989;80:1675-80.

7 Bigger JT. Prevalence and possible mechanisms of ventricular arrhythmias in congestive heart failure. Royal Society of Medicine Services. Round table series. New Society of Medicine Services. Round table series. New mias in heart failure, new frontiers, 1988:11-27.

8 Califf RM, McKinnis RA, Burks J, et al. Prognostic implications of ventricular arrhythmias during 24 hour ambulatory montoring in patients undergoing cardiac 1982;50:23-31.

9 Swerdloe CD, Winkle RA, Mason JW. Determinants of survival in patients with ventricular tachyarrhythmias. N Engl J Med 1983;308:1436-42.

10 Huang SK, Messer JV, Denes P. Significance of ventricular tachycardia in idiopathic dilated cardiomyopathy observations in 35 patients. Am J Cardiol 1983;51:507-12.

11 WHO. Sudden cardiac death. Report of a WHO scientific group. WHO technical report series. 1985:726.

12 Sideris DA. The importance of blood pressure in the emergence of arrhythmias. Eur Heart J 1987;8 (Suppl D): $129-31$.

13 James MA, Jones JV. Ventricular arrhythmia in untreated newly presenting hypertensive patients compared with a matched normal population. J Hypertens 1989;7:409-15.

14 Olshausen K, Schwartz F, Appelbach J, Rohrig N, Kramer $B$, Kubler $W$. Determinants of the incidence of severity of ventricular arrhythmias in aortic valve disease. $A m$ Cardiol 1983;51:1103-9.

$15 \mathrm{Lab}$ MJ. Contraction-excitation feedback in myocardium: physiological basis and clinical relevance. Circ Res 1982; 50:757-66.

16 Franz MR, Burkhoff D, Yue DT, Sagawa K. Mechanically induced action potential changes and arrhythmia in isolated and in situ canine heart. Cardiovasc Res 1989;23: lated and

17 Levine JH, Guarnieri T, Kadish AH, White RI, Calkins H, Kan JS. Changes in myocardial repolarisation in patients Kan JS. Changes in myocardial repolarisation in patients undergoing baloon valvuloplasty for congenital pulmonary stenosis: evidence for contraction-ex

18 Taggart P, Sutton PMI, Treasure T, et al. Monophasic action potentials at discontinuation of cardiopulmonary action potentials at discontinuation of cardiopulmonary man. Circulation 1988;77:1266-75. 
19 Dean JW, Lab MJ. Arrhythmia in heart failure: the role of mechanically induced changes in electrophysiology. Lancet 1989;i:1309-12.

20 Calkins H, Maughan L, Weisman HF, Sugiura S, Sagawa K, Levine JH. Effects of acute volume load on refractoriness and arrhythmia development in isolated chronically infarcted canine hearts. Circulation 1989;79:687-97.

21 Taggart P, Sutton P, John R, Lab M, Swanton H. Monophasic action potential recordings during acute changes in ventricular loading induced by the Valsalva manoeuvre. Br Heart J 1992;67:221-9.

22 Tyberg JV, Forrester JS, Parmley WW. Altered segmental function and compliance in acute myocardial ischemia. Eur J Cardiol 1974;1:307-17.

23 Forrester JS, Wyatt HL, da Luz PL, Typerg JV, Diamond GA, Swan HJC. Functional significance of regional GA, Swan HJC. Functional significance of regional ischemic

24 Eaton LW, Weiss JL, Bulkey BH, Garrison JB, Weisfeldt ML. Regional cardiac dilatation after acute myocardial infarction: recognition by two-dimensional echocardiography. N Engl J Med 1979;300:57-62.

25 Meizlish JL, Berger HJ, Plankey M, Errico D, Levy W, Zaret BL. Functional left ventricular aneurysm formation after acute transmural myocardial infarction. $N$ Engl Med 1984;311:1001-6.

$26 \mathrm{Han} \mathrm{J}$, Moe GK. Nonuniform recovery of excitability in ventricular muscle. Circ Res 1964;14:44-60.

27 Hansen DE, Craig CS, Hondeghem LM. Stretch-induced arrhythmias in isolated canine ventricle. Evidence for the arrhythmias in isolated canine ventricle. Evidence for the
importance of mechanoelectrical feedback. Circulation importance of mech

28 Kuo CS, Munakata K, Reddy CP, Surawicz B. Characteristics and possible mechanism of ventricular arrhythmia dependent on the dispersion of action potential durations. Circulation 1983;67:1356-67.

29 Janse MJ, Wit AL. Electrophysiological mechanisms of ventricular arrhythmias resulting from myocardial ischemia and infarction. Physiol Rev 1989;69:1049-1169.

30 Allessie MA, Bonke FIM, Schopman FJG. Circus movement in rabbit atrial muscle as a mechanism of tachycardia: in. The role of nonuniform recovery of excitability in the occurrence of unidirectional block, as
studied with multiple microelectrodes. Circ Res 1976; studied with

31 Gough WB, Mehra R, Restivo M, Zeiler RH, El-Sherif N.
Reentrant ventricular arrhythmias in the late myocardial infarction period in the dog: 13 correlation of activation and refractory maps. Circ Res 1985;57:432-42.

32 Bogen DK, Rabinowitz SA, Needleman A, McMahon TA, Abelmann WH. An analysis of the mechanical disadvantage of myocardial infarction in the canine left ventricle. Circ Res 1980;47:728-41.

33 Hoffman BF, Cranefield PF, Lepeschkin E, Surawicz B, Herlich HC. Comparison of cardiac monophasic action potentials recorded by intracellular and suction elecpotentials recorded by intracellular and
trodes. Am J Physiol 1959;196:1297-301.

34 Olsson SB, Edvardsson N, Hirsch I, Blomstrom P. Methodological aspects of invasive evaluation of myocardial odological aspects of invasive evaluation of myocardial repolarisation. In: Butrous GS, Schwartz PJ, eds. Clinical aspects of ventriculd

35 Calkins H, Maughan WL, Kass DA, Sagawa K, Levine JH. Electrophysiological effect of volume load in isolated canine hearts. Am J Physiol 1989;256:1697-706.

$36 \mathrm{Lab}$ MJ. Contribution of mechano-electric coupling to ventricular arrhythmias during reduced perfusion. Int $J$ Microcirc Clin Exp 1989;8:433-42.

37 El-Sherif N, Zeiler RH, Craelius W, Gough WB, Henkin R. QTU prolongation and polymorphic ventricular tachyarrhythmias due to bradycardia-dependent early afterdepolarizations. Afterdepolarizations and ventricular depolarizations. Afterdepolarizations
arrhythmias. Circ Res 1988;63:286-305.

38 Levine JH, Spear JF, Guarnieri T, et al. Cesium chloride induced long $\mathrm{T}$ syndrome: demonstration of afterinduced long $T$ syndrome: demonstration of afterdepolarizations and

39 Craelius W, Chen V, El-Sherif N. Stretch activated ion channels in ventricular myocytes. Biosci Rep 1988;8 407-14.

40 Lab MJ, Allen DG, Orchard CH. The effects of shortening on myoplasmic calcium concentration and on the action potential in mammalian ventricular muscle. Circ Res 1984;55:825-9.

41 Mullins LJ. The generation of electric currents in cardiac fibres by Na/Ca exchange. Am J Physiol 1979;236:103-10.

42 Colquhoun D, Neher E, Reuter H, Stevens CF. Inward current channels activated by intracellular calcium in cultured cardiac cells. Nature 1981;294:752-4.

43 Webster MWI, Fitzpatrick MA, Nicholls MG, Ikram H, Wells JE. Effect of enalapril on ventricular arrhythmias in congestive heart failure. Am J Cardiol 1985;56:566-9. 